\title{
A Study on the Role of Public and Private Sector Radio in Women's Development with Special Reference to India
}

\author{
By Afreen Rikzana Abdul Rasheed ${ }^{*}$ \\ Neelamalar Maraimalai ${ }^{\dagger}$
}

\begin{abstract}
Radio plays an important role in the lives of women belonging to all sections of society, but especially for homemakers to relieve them from isolation and help them to lighten their spirit by hearing radio programs. Women today play almost every role in the Radio Industry - as Radio Jockeys, Program Executives, Sound Engineers and so on in both public and private radio broadcasting and also in community radio. All India Radio (AIR) constitutes the public radio broadcasting sector of India, and it has been serving to inform, educate and entertain the masses. In addition, the private radio stations started to emerge in India from 2001. The study focuses on private and public radio stations in Chennai, which is an important metropolitan city in India, and on how they contribute towards the development of women in society.
\end{abstract}

Keywords: All India Radio, private radio station, public broadcasting, radio, women's development

\section{Introduction}

Women play a vital role in the process of a nation's change and development. The Indian Constitution provides equal status to men and women. The status of women in India has massively transformed over the past few years in terms of their access to education, politics, media, art and culture, service sectors, science and technology activities etc. (Agarwal, 2008). As a result, though Indian women have the responsibilities of maintaining their family's welfare, they also enjoy more liberty and opportunities to chase their dreams.

Due to the population crisis in India, women's development initiatives can be sometimes misleading; hence, it is important to plan these initiatives using diverse perspectives that can lead to success in the long run. To eliminate all forms of discrimination against women and to ensure their active participation in public activities, the government of India developed the National Policy for Empowerment of Women in 2001. Women are slowly occupying important positions in terms of governance and democracy in spite of facing several socio-economic and political obstacles (Kumar \& Singh, 2008). It is crucial to develop the status of women as they constitute half of the nation's population, and they can greatly influence the remaining half, thus contributing to the holistic development of the country. Women can be empowered through simple techniques, such as providing access to information, knowledge and education using communication channels. Unfortunately, women (especially in rural areas) are often deprived of minimum

*PhD Research Scholar, Department of Media Sciences, Anna University, India.

${ }^{\dagger}$ Assistant Professor, Department of Media Sciences, Anna University, India. 
facilities to access such content (Sharma, 2015). The mass media can be used as an effective tool for social change in India, and the National Plan of Action for Women in 1976 provided sufficient direction for media planning and communication priorities for women in India. Radio, in comparison to other mass media channels, has the potential to reach people dwelling in deprived areas. In particular, women specific programs when aired on the radio can provide access to information that can lead to empowerment and make them more self-reliant (Rathod, 2009). Through radio programs, women residing in underdeveloped areas are able to learn about their rights and gain awareness about problems faced in the family and society.

In India, radio broadcasting was initially started in forms of Radio clubs in 1923. Later the Indian Broadcasting Service (IBS) was started in the year 1927 as a unified body handling the public broadcasting system in India (Bhatnagar, 2001). Since the early days, public radio stations have played a major role in developing the lives of women in India. In 1936, the Indian Broadcasting Service was rename as All India Radio (AIR), which is also known as "Aakashvaani" (Voice from the sky). The prime objective of AIR is to provide listeners with information, education and entertainment in their most preferred way. According to the 2016 annual report of AIR, their programs broadcasted in 23 languages and 128 dialects, reaching almost the entire population of India through news, music and other genres of radio programs. AIR is also very popular among rural and tribal people, making it ideal for spreading awareness in the entertainment genre.

After the FM revolution in early 2008, private FM got started in various cities across India. The arrival of private FM radio stations revolutionized the radio industry and attracted more radio listeners.

In Chennai, AIR programs are broadcasted under both Amplitude Modulation (AM) and Frequency Modulation (FM). Primary channels Chennai A and Chennai B are broadcasted through AM, while the channels Rainbow FM and FM Gold fall under the FM broadcasting. ${ }^{1}$ There are a total of 10 FM radio stations in Chennai, of which 8 stations are private radio stations and 2 stations are public radio stations. The list of FM radio stations is given in Table 1.

Table 1. List of Public and Private FM Radio Stations in Chennai

\begin{tabular}{|l|l|l|}
\hline $\begin{array}{l}\text { SI. } \\
\text { No. }\end{array}$ & $\begin{array}{l}\text { Private FM Radio Stations } \\
\text { (frequency in MHz) }\end{array}$ & $\begin{array}{l}\text { Public FM Radio Stations } \\
\text { (frequency in MHz) }\end{array}$ \\
\hline 1. & Suryan FM (93.5) & FM Rainbow (101.4) \\
\hline 2. & Radio Mirchi (98.3) & FM Gold (100.5) \\
\hline 3. & Radio One (94.3) & \\
\hline $\mathbf{4 .}$ & Big FM (92.7) & \\
\hline $\mathbf{5 .}$ & Radio City (91.1) & \\
\hline $\mathbf{6 .}$ & Hello FM (106.4) & \\
\hline $\mathbf{7 .}$ & Chennai Live (102.4) & \\
\hline $\mathbf{8 .}$ & Fever FM (91.9) & \\
\hline
\end{tabular}

\footnotetext{
${ }^{1}$ All India Radio. (2017). Retrieved from www.allindiaradio.gov.in.
} 
Among the list of FM Stations in Chennai, Fever FM and Radio One are broadcasted in Hindi and Chennai Live in English, while the other stations air their programmes in the regional language of Chennai - Tamil.

AIR programs for women generally concentrate more on information and education. On the other hand, private FM stations air women-based programs in "infotainment" format, thereby breaking stereotypes and increasing interest among the women listeners in both urban and rural areas. Both private and public radio sectors air programs and events related to women's development in order to bring change in their lives and involve the listeners in the development process. With women centric programs gaining more importance within the radio industry, it is essential to analyse the present scenario of radio in India. Hence, the study aims to analyse the importance given to women-focused radio programs in public and private radio stations in Chennai.

\section{About AIR}

AIR follows a Three Tier Broadcasting system, as follows:

1. First Tier Broadcasting provides national programs in Medium WaveAmplitude Modulation (AM).

2. Second Tier Broadcasting provides programs for regional and sub-regional stations listeners in their own languages to promote their cultural facts.

3. Third Tier Broadcasting happens through Local Radio Stations (LRS), which air programs in Frequency Modulation (FM) wave in 420 AIR stations in each and every small town throughout India.

All India Radio has always been a pioneer and is in sync with growing technology by broadcasting its programs through radio devices, mobile devices, DTH, internet radio and smart phone applications.

In AIR, there is a separate unit for news production, which is known as the Air News Services Division and is in both Indian languages and foreign languages.

There are many sections in AIR for programming, including talks in Tamil and English, education broadcast, law, western music, drama, children, folk music, science, features, senior citizens, sports, light music, music, folk music, Telugu, Malayalam, Kannada, etc. The special audience programs are aimed at rural populations, youth, and women and focus no topics such as health, farming, the home, family and welfare. FM Rainbow operates in 18 FM channels from different regions for rural as well as urban populations, whereas FM Gold programs are broadcast from Chennai, Delhi, Kolkata and Mumbai. ${ }^{2}$

In AIR, the program schedule is termed as Fixed Point Chart (FPC). The FPC is changed once every three months. At first, the genre and topic of the radio programs are decided, then the program cue sheets are approved from the higher officials (Director General). The flow chart of programming Wing of AIR Chennai is given in Figure 1.

${ }^{2}$ All India Radio. (2017). Retrieved from www.allindiaradio.gov.in. 
Figure 1. Programming Wing of AIR Chennai

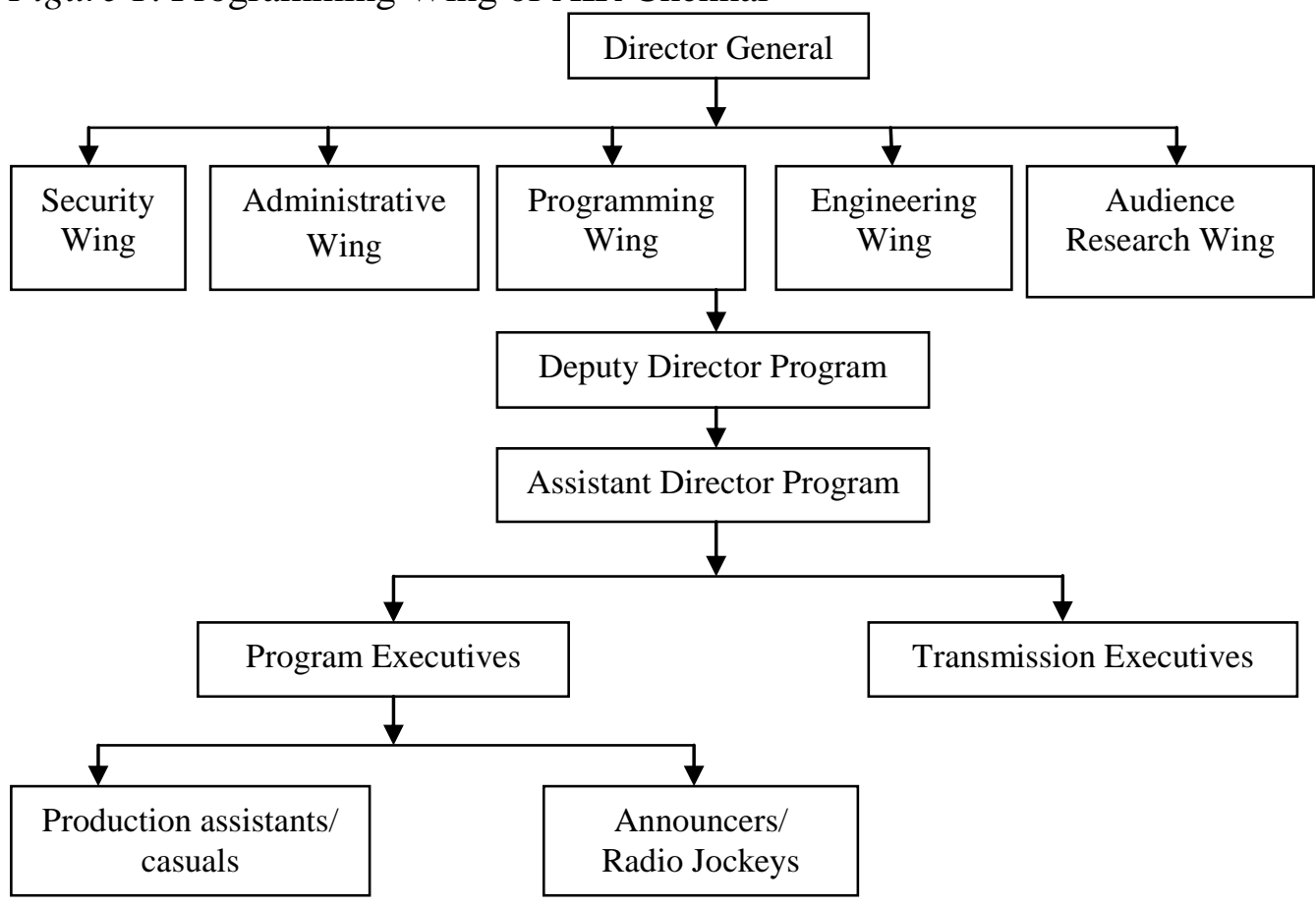

\section{Women's Section of AIR}

In the women's section, radio programs are produced and presented by women. The first program of this section was launched in the year 1938; during that time, it was aired once in a fortnight. Now, it follows the genre of radio magazine type of program and is broadcasted on one of the primary channels, Chennai A $(720 \mathrm{KHz})$. At present, there are three women working under the supervision of the Assistant Director Program. The radio magazine for women includes interviews, discussions, debate, drama and audio presentation. The program content is segmented under six topics, namely female pioneers, sports women, daily life struggles, information catalogue, legal awareness and human interest pieces about common women like flower vendors and fisherwomen. The time slot schedule of this radio magazine program is $1 \mathrm{pm}-2 \mathrm{pm}$ from Monday to Friday.

\section{Youth Section of AIR}

This section of AIR concentrates on youth empowerment. The time slot schedule of the youth program is $6 \mathrm{pm}-7 \mathrm{pm}$ from Monday to Friday aired in one of the primary channels, Chennai $\mathrm{B}(1017 \mathrm{KHz})$. The program genres are mostly quiz, discussion, interview, drama, talks and feature. However, the programs contain less information for women. 


\section{FM Rainbow}

In India, AIR launched its first FM channel in 1977 in Chennai and started broadcast services based on FM technology in 1984. AIR started the FM Rainbow channel on February, 1993. When compared to AM transmission, the listeners of FM channel receive noise-free reception quality. FM Rainbow in general provides programs in different informal programming styles and new genres of entertainment that grab the attention of youth.

The programming of FM Rainbow includes pop music, film songs, classical and devotional music, informal chat shows, phone-in programs, and more. Each program is broadcast for one hour. In between each program, news is broadcast live for three minutes.

In FM Rainbow, there are no fixed radio jockeys for a particular program, and it is updated daily according to the programming cue sheet and FPC.

The FM Rainbow channel is initiated from 15 centres in various parts of India, located in Delhi, Mumbai, Chennai, Kolkata, Bangalore, Lucknow, Panaji, Jalandhar, Cuttack, Kodaikanal, Tiruchirapalli, Coimbatore, Vishakhapatnam, Puducherry and Vijayawada. AIR Delhi Rainbow is relayed from Mussorie, Kanpur, Aligarh, Kasauli, Kursleong, Leh, Aurangabad, Kochi, Cherrapunji and Shillong and partly from Hyderabad, Bhadrava, Poonch, Rajauri, Naushera, RK Srinagar, RK Jammu, Jhansi, Dharamshala, and Bhatinda. ${ }^{3}$

Table 2 represents the number of women working in the four sections of All India Radio, Chennai. This table shows that there are more opportunities for women in public radio sector when compared to men.

Table 2. Representation of Women in Four Sections of AIR Chennai

\begin{tabular}{|c|c|c|c|c|c|}
\hline $\begin{array}{l}\text { SI. } \\
\text { No. }\end{array}$ & Section Name & Designation & Female & Male & Total \\
\hline \multirow{2}{*}{1.} & \multirow{2}{*}{ FM Rainbow } & Radio Jockeys & 25 & 30 & \multirow{2}{*}{56} \\
\hline & & ADP & 1 & 0 & \\
\hline \multirow{2}{*}{2.} & \multirow{2}{*}{ Women's Section } & Announcers & 3 & 0 & \multirow[t]{2}{*}{4} \\
\hline & & ADP & 1 & 0 & \\
\hline \multirow{2}{*}{3.} & \multirow{2}{*}{ Youth Section } & Announcers & 2 & 0 & \multirow[t]{2}{*}{3} \\
\hline & & Program Executive & 0 & 1 & \\
\hline 4. & AIR Chennai & $\begin{array}{l}\text { Transmission } \\
\text { Executives }\end{array}$ & 5 & 4 & 9 \\
\hline \multicolumn{3}{|c|}{ Total } & 37 & 35 & 72 \\
\hline
\end{tabular}

\section{Research Wing}

In All India Radio, the research wing is named the Audience Research Unit (ARU). Most of the AR Units are headed by the Deputy Director of Audience Research or an Audience Research officer, two Investigators and supporting staff.

ARU Chennai conducts Radio Audience Surveys (RAS) regularly for all the AIR channels (Primary channel, VividhBharati, FM Rainbow and FM Gold).

${ }^{3}$ All India Radio. (2017). Retrieved from www.allindiaradio.gov.in. 
There are only two ARUs (Chennai and Tiruchirapalli) for 10 AIR Stations in Tamil Nadu (Chennai, Tiruchirapalli, Madurai, Coimbatore, Kodaikanal, Ooty, Nagercoil, Dharmapuri, Tuticorin and Karaikal). All the State capital stations have an ARU wing, and so now there are 26 units functioning. Wherever there is a requirement, AIR conducts an RAS every year. FGD (Focus Group Discussion) is another technique followed by the ARU to find the pulse of the audience. Telephone surveys are conducted regularly for special programmes, and field surveys are conducted for special audience programmes like Farm and Home, News and Youth.

\section{About Private Radio Stations in Chennai}

In the private FM Policy, the focus shifted from Medium Wave (MW), which is used for amplitude modulation (AM), to Frequency Modulated (FM) wave, which is used for very high frequency. It was planned to improve programme content, provide a wider choice of programmes, improve broadcast quality, enhance technical features, renew old and obsolete equipment, and add new facilities at radio stations. The expansion of FM radio broadcasting services through private agencies was approved by the Indian government in different phases. The first phase -FM Phase I- was approved by the Government of India in July 1999. The FM Phase I Policy provided for selection of successful bidders through open option. The Phase I policy met with limited success throughout India. A total number of 21 channels are operational in 12 cities under this scheme.

The improved FM Phase II Policy was notified in July 2005 after considering the recommendations of Dr. Amit Mitra, the Committee, and TRAI (Telecom Regulatory Authority of India). FM Policy Phase II has been well received by all stake holders. It has resulted in huge growth in the FM radio industry. However, many cities still remained uncovered by the private FM radio broadcasting. ${ }^{4}$

Table 3 provides the information about the number of private radio stations started in Phase I and Phase II in Chennai.

Table 3. List of Private Radio Stations in Phase I and Phase II

\begin{tabular}{|l|l|}
\hline Phase I & Phase II \\
\hline Radio-mirchi $(98.3 \mathrm{MHz})-2003$ & Big-FM $(92.7 \mathrm{MHz})-2006$ \\
\hline Suryan FM $(93.5 \mathrm{MHz})-2003$ & Radio-city $(91.1 \mathrm{MHz})-2006$ \\
\hline \multirow{5}{*}{} & Hello FM-FM $(106.4 \mathrm{MHz})-2006$ \\
\cline { 2 - 2 } & Radio-one $(94.3)-2007$ \\
\cline { 2 - 2 } & Chennai live $(102.4 \mathrm{MHz})-2008$ \\
\cline { 2 - 2 } & $\begin{array}{l}\text { Aahaa FM }(91.9 \mathrm{MHz})-2007 . \text { This } \\
\text { station has been acquired by Fever FM } \\
\end{array}$ \\
& (91.9 MHz) in October 2015. \\
\hline
\end{tabular}

\footnotetext{
${ }^{4}$ All India Radio. (2017). Retrieved from www.allindiaradio.gov.in.
} 


\section{Suryan FM (93.5 MHz)}

Sun Network group, a veteran in Television Broadcasting launched its radio channel -Suryan FM - in the year 2003 under FM Phase I policy in Chennai, Madurai, Coimbatore, Tirunelveli, Tuticorin in TamilNadu and Pondicherry. In addition to the conventional radio, Suryan FM was also broadcasted through television frequency band as a part of their promotional strategy for the first few months. The organisational structure of Suryan FM is given in Figure 2.

Figure 2. Organizational Chart of Suryan FM

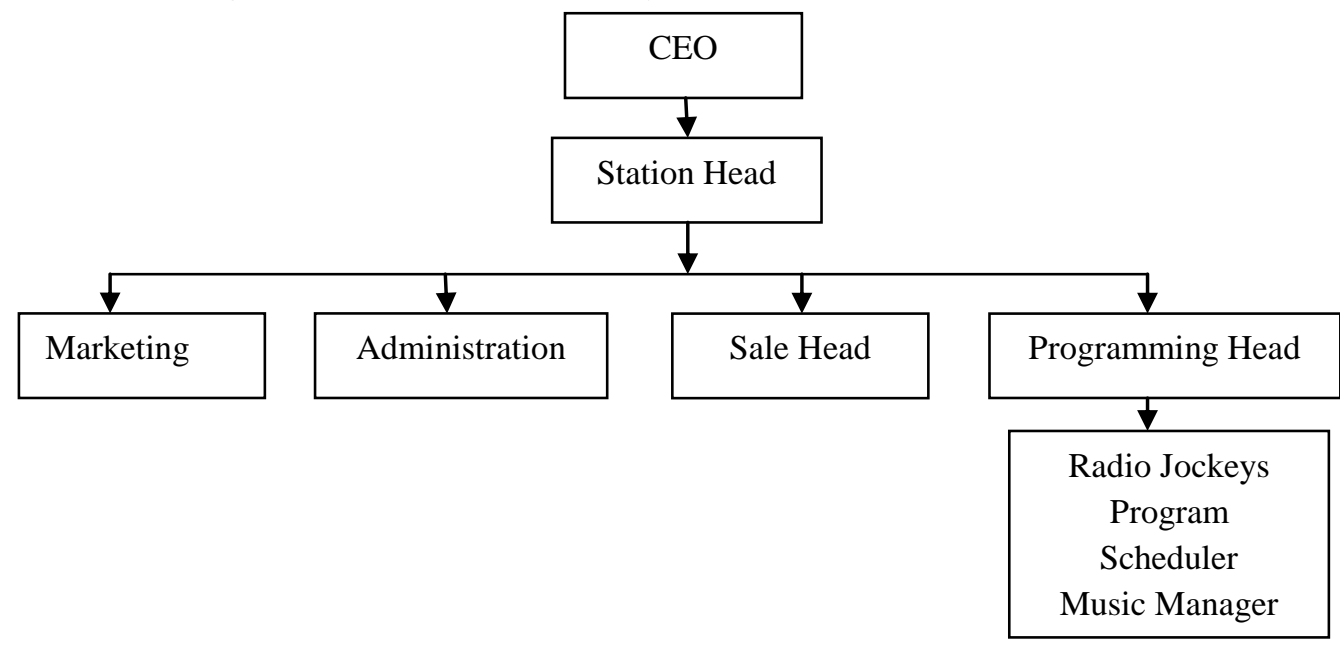

\section{Big FM (92.7 MHz)}

The launch of Big FM Radio station in Chennai occurred in September 2006, and it has expanded at a phenomenal pace, launching 45 stations in a record-breaking time period of 18 months. Big FM is a nationwide private FM radio station in India owned by the Reliance Network group. This is the only private FM radio station that is being broadcast from Srinagar and Jammu in Jammu \& Kashmir state. In Tamil Nadu, Big FM operates only in Chennai. The organisational setup of Big FM is shown in Figure 3.

Figure 3. Organizational Chart of Big FM

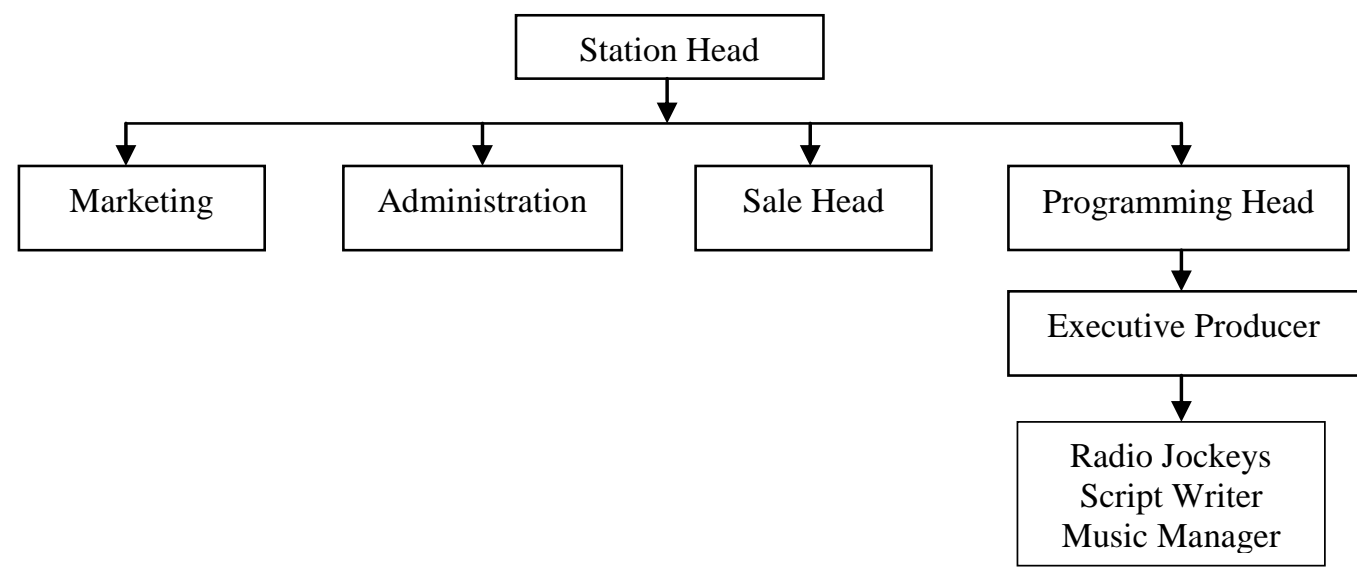




\section{Radio City (91.1 Mhz)}

Radio City is owned by the Jagran subsidiary company called Music Broadcast Limited (MBL) and started in the year 2006 in Chennai. Radio City offers programs in online media through the website planetradiocity.com and now has 42 web radio stations. There are 39 FM stations of Radio City operating in several parts of India. The organisational setup of Radio City is shown in Figure 4.

Figure 4. Organizational Chart of Radio City

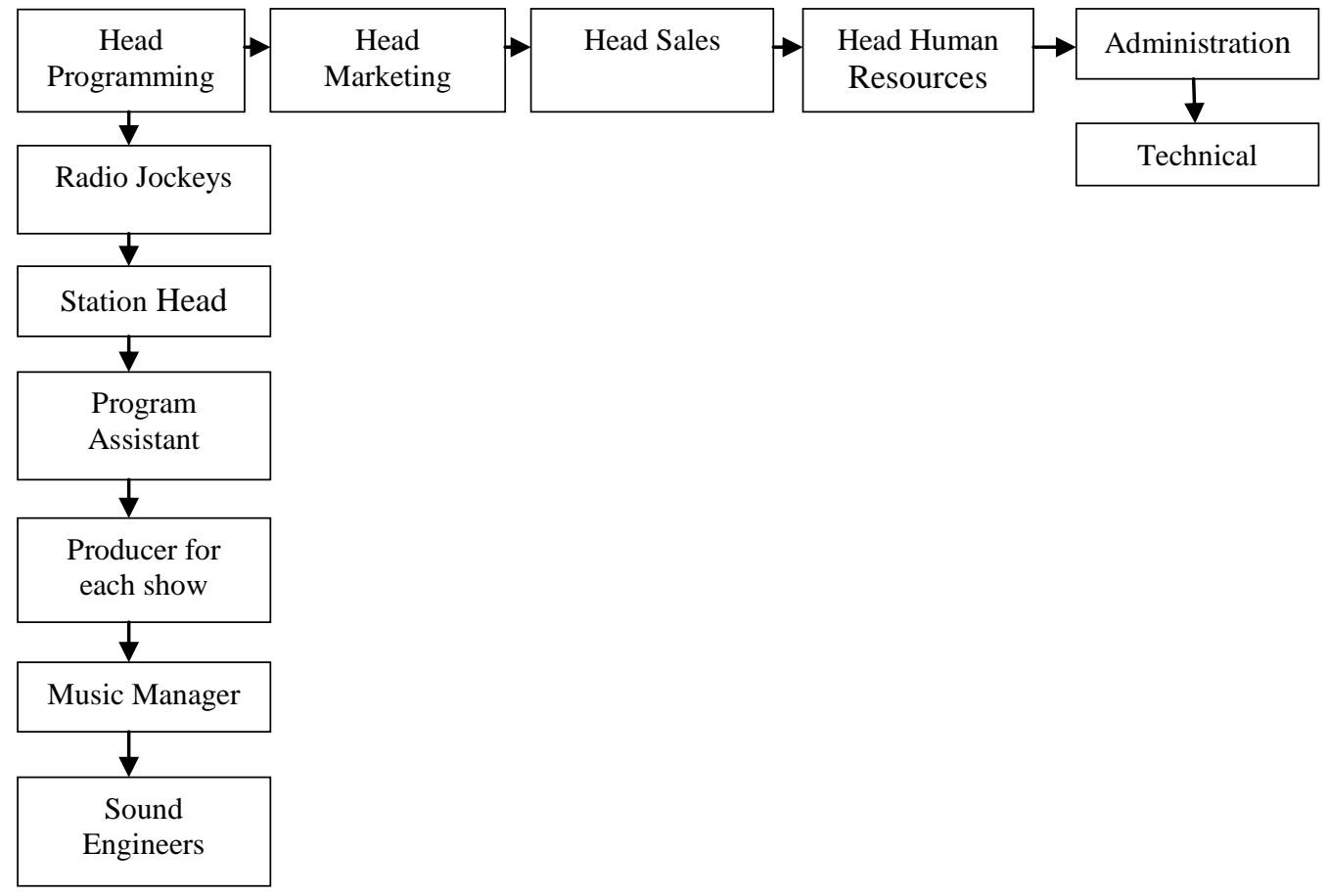

\section{Hello FM (106.4 MHz)}

Hello FM operates its various stations in different parts of Tamil Nadu, such as Chennai, Madurai, Trichy, Triunelveli Thoothukudi, Coimbatore and Pondicherry-Union Territory. It began in 2006 in Chennai. Hello FM is owned by the Malar Publication, and it is operational only in Tamil Nadu. The organisational structure of Hello FM is given in Figure 5. 
Figure 5. Organizational Chart of Hello FM

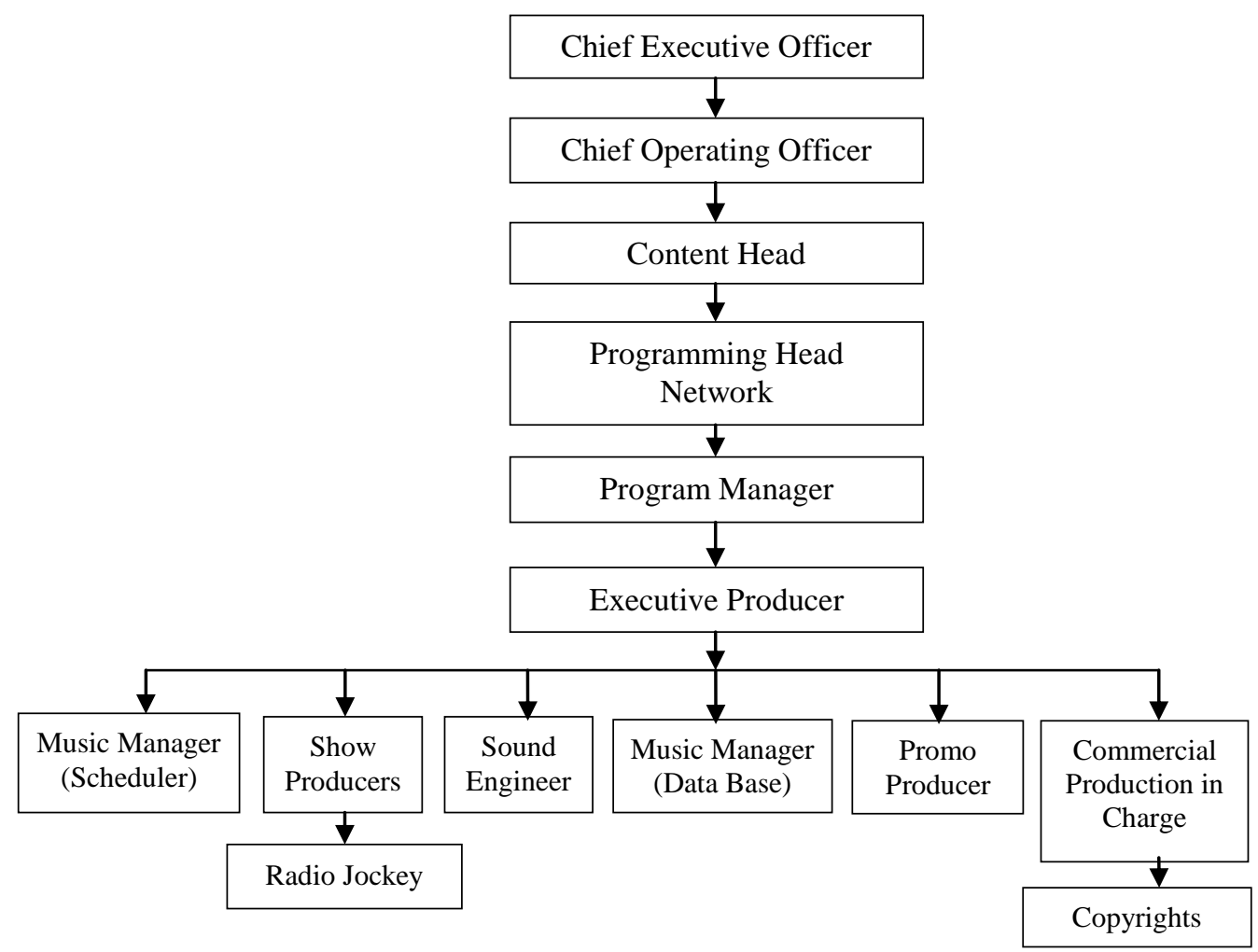

Table 4 provides information about the representation of women employees in four private FM stations in Chennai.

Table 4. Representation of Women in Four Private Radio Stations in Chennai

\begin{tabular}{|l|l|l|c|c|}
\hline SI.No. & Station Name & Designation & Female & Total \\
\hline \multirow{2}{*}{$\mathbf{1 .}$} & Big FM & Radio Jockeys & 5 & \multirow{2}{*}{6} \\
\cline { 3 - 4 } & & Program Executive & 1 & \\
\hline \multirow{2}{*}{$\mathbf{3 .}$} & Radio City & Radio Jockeys & 3 & \multirow{2}{*}{4} \\
\cline { 3 - 4 } & & Program Executive & 1 & \\
\hline 4. & Hello FM & Radio Jockeys & 4 & \multirow{2}{*}{4} \\
\cline { 3 - 4 } & & Program Executive & 0 & 3 \\
\hline Total & Suryan FM & Radio Jockeys & 3 & $\mathbf{1 7}$ \\
\hline
\end{tabular}

\section{Review of Literature}

This section consists of a literature review dealing with radio broadcasting in the global and Indian contexts, as well as radio broadcasting directed at women. 


\section{Radio Broadcasting for Women}

Mitchell (2008) discusses women's alternative radio, which involves participatory practices and alternative representations to the mainstream media, and infers that women have a right to broadcast in their own terms, own voices, articulate their concerns and tell their own stories in order to represent their struggles and achievements. Women's radio is used as a major tool for women's self-development. The production is thus more about offering training and skills, collective working and problem solving.

Lacey (2006) discussed the relationship between women and radio, as radio is well-suited for promoting interests and expressions of women. Women's radio, such as BBC Radio 4 (Women's Hour), has played an important role in changing the lives of women. There are other types of women's radio as well, including women's music radio and women's business radio, that showcase music produced by women and interviews of successful women, respectively. Online radio continues to be an important platform that aids women interacting with other women in the multimedia world.

Skoog (2009) stated that BBC Radio had an exclusive program targeting every household and working women named "Women's Hour," which was started in October 1946. The program was broadcasted 2-3pm, Monday to Friday. The program focused on domestic issues. It has also covered women's conferences on topics such as social welfare, fuel rationing and household economy. Women's Hour programs were mostly based on listeners' feedback letters. Currently, Women's Hour is aired on weekdays at $10 \mathrm{am}$ and weekends at $4 \mathrm{pm}$ on Radio 4 (Vickery, 2016).

Bell (2008) has done a study documenting the history of women who have worked in various BBC channels through in-depth interviews and case study methodology. BBC Channel 4 has a successful history of making authoritative series by and for women, including the protest experience of family and relationships within the society. She has concluded that the experiences and opinions of women as professionals in history, media and acting are crucial.

Not only the radio stations of developed countries such as the British Broadcasting Corporation, the radio stations of third world countries including Africa also focus on women's development. Bosch (2013) has mentioned that the exclusion of women in the public sphere in Africa has increased the relevance of the consideration of women radio listeners in Africa. Women do not necessarily tend to listen to the radio only for gender-specific programs, but they do come into formation as a social collective, as radio defines the acceptable limits of their roles and participation in society. Radio listening through mobile devices has changed women's private listening practices and has increased interactivity with radio stations in relation to social space. Somolu (2013) has conducted a study among Nigerian women using the focus group methodology and concluded that the convergence between radio and other internet-based tools have limited effects in making radio content more accessible. He has also identified that radio programs are encouraging women in business.

Odunola, Babafemi, and Lois (2015) have discussed political radio programs in Nigeria, which have been effective in organising women for political 
participation. The political radio programs were identified to change the negative outlook of women's political participation and inspire them to compete in elections.

\section{Public Service Broadcasting}

According to Bora (2011), under Public Service Broadcasting (PSB), radio is a conventional electronic medium, airing programs that cannot be assessed by the existing criteria used for the evaluation of radio content, as it has been primarily designed for commercial broadcasting programs. Public radio stations generally air programs that not only entertain, but also educate and inform the public. The availability of tools and skills in PSB contribute to the growth of a standardized social system in which traditional welfare related messages are integrated by promoting opportunities for all individuals equally. According to the study, PSB is expected to play a major role in resolving cultural dilemmas and meeting the cultural needs in the future.

Amoeda (2010) has analysed the growth and current condition of the public radio in Spain. The first autonomous radio institution, Radio Television Española (RTVE), follows the rules of public service adapted to the cultural, social and political circumstances of their respective regions. The digitalization of radio production and the new online radio platforms have aided in the development of several important social requirements that were not possible earlier. Because of its proximity to the audience, regional public radio is both a witness to the present and the guardian of regional tradition.

Lai (2014) has discussed Police Broadcasting Service (PBS) and the oldest traffic radio station used in terms of giving professional knowledge and information among other radio stations. A Non-Profit Organization (NPO) in Taiwan conducts health communication campaigns aiming to create awareness of colorectal cancer and prevention measures using PBS for colorectal cancer patients and their family members. Under the influence of this successful campaign of PBS, other radio stations in Taiwan have also tried to produce programs for education and awareness among radio listeners regarding health communication.

\section{Radio Broadcasting in India}

Regarding radio broadcasting in India, many revealing studies have been done. For instance, Kumar (2013) has discussed the diversity of Public Service Broadcaster (PSB) in India and the policy interventions aimed at strengthening the PSB of the nation. The PSB in India includes All India Radio (AIR) and Doordarshan (DD). The ideas and suggestions given by various commissions and committees in relation to PSB led to the development of an autonomous organisation - Broadcasting Corporation of India, namely Prasar Bharathi. Kumar concludes that the PSB should be strongly improvised in several aspects, namely digitization, marketing, legal, financial and technical security in order to compete with the private broadcasters. 
AIR brings about the nation's interest by broadcasting public culture programs in a unique and creative way for competing in all aspects of development in radio, including commercial, community and internet (Thomas, 2013). Earlier, the radio medium was used as a very powerful education tool in India (1947) during independence, owing to the country's high illiteracy rate. However, the educational role of AIR was gradually reduced after independence, due to the influence of the political agenda transforming AIR as a propaganda channel for the government of India. The AIR's FM listenership has increased from 4.6 million in 1995 to 10.1 million in March 1998 in major cities (Thussu, 1999).

Educational projects hold a strong prominence in the AIR radio programmes. "Project in Radio Education for Adult Literacy" (PREAL) is one such well known initiative done by the AIR.

Agrawal (2007) has discussed about the AIR intervention in PREAL conducted in four states across India. In this project, public radio broadcasting was used to facilitate teaching and learning experiences of women, aiming to increase their knowledge and decrease the illiteracy rate.

On the whole, the literature reveals that the radio medium has played a greater role in Indian women's development. Rogers (2003) formulated the diffusion of innovation theory that outlines the four major factors - invention, diffusion or communication through the social system, time and consequences - that influence the society to accept and utilize a particular innovation. Any new innovation in general is observed to travel through five different types of adopters, namely innovators, early adopters, early majority, late majority and laggards under the influence of mediators such as gatekeepers, opinion leaders and intermediaries.

The review of literature reveals that the radio medium has the ability to travel through all these stages and to reach and help women of developed as well as developing nations.

Other than public radio broadcasters, there are many private radio stations in India that broadcast the programs in interesting ways and Chatterji (2008) deals with the expansion of FM Radio broadcasting through private sectors and liberalised policy. He observes that the main objectives for starting private FM stations were to make quality programs with new content and to encourage new talent and generate employment opportunities. The popularity of private FM is quite high and these stations primarily differ from AIR in terms of programming and content, making it lively, casual and entertaining. According to the 2008 Indian Readership Survey (IRS), the private FM station (Radio Mirchi) had the highest listenership during the period of 2007-2008 (Ranganathan, 2010).

\section{Methodology}

The methodology used for this study is in-depth interview. In-depth interviews were used to collect information regarding the perception, views and experiences of people working in Chennai AIR organization and in private radio stations such as Big FM, Suryan FM, Radio City and Hello FM. For this 
study, in-depth interviews were conducted with 25 people present in different sections of AIR, such as Assistant Directors, Program Executives, Announcers or Radio Jockeys and the Deputy Director of the Research. In the private radio sector, Radio Jockeys and Program producers were interviewed. The interviews were scheduled during February-March of 2017. Each interview took 30 minutes to 1 hour. A semi-structured questionnaire majorly consisting of open ended question was developed and used for the interviews.

\section{Analysis and Interpretation}

\section{In-depth Interview-Public Radio Sector}

Here the views shared by people working in AIR regarding their views about women's development, views about women-related programs and the role of radio in women's development are given.

Women's development in India. In India, women's development is still not at the peak when compared with other developing countries. Women are constrained, due to cultural and family circumstances, but a few have witnessed empowerment within their own boundaries. This is because women's growth is proportional to the support gained from their family. Thus, women's development initiatives need a major revamp, where every woman is encouraged to take up her rights and act.

In Tamil Nadu, women's development has been viewed among women in cities, but basic education is still missing in rural villages. There needs to be a major change in the educational system in order to provide fulfilment and reach every woman to enhance her life. Only effective education can empower women's self-management and decision-making skills. In this way, women's development can be attained. Also there must be a good working environment to inspire the talent of women, rather than degrading them by nature of their sex. In India, the view of women being considered as a weaker sex still needs to be changed, and violence against them needs to be destroyed from its roots.

Women related programs in AIR. Radio is mostly preferred by a lot of women due to their fondness for gaining new information. Radio jockeys in AIR are trained to do all kinds of radio programs. Their programs disseminate awareness by providing information and entertainment to listeners.

In the women-focused radio programs, women from all levels of society such as government officials, business women, doctors, lawyers, flower vendors, to mention a few, are interviewed. Women's development needs to occur in all sectors, from politics to the home. Special discussion segments on radio programs have concerned widows' remarriage, love marriages etc. in order to help listeners know about their legal rights.

One particular program was targeting deprived people in society, such as transgender people, street dwelling women and children, tribal people, and 
artist women. This program had a positive reception according to social networks and letters sent to radio stations. Following this, in 2010 a program for women called "Phoenix" and about real life heroines was aired. It focused on women who have faced issues, like harassment and violence, and how they overcame them. All 25 episodes of the program have motivated women in every possible way of their life and had a great reputation amongst the listeners.

Also radio programs based on traditional values for food, dress, and cultural arts, etc. are being produced and occupy morning time from $7 \mathrm{am}-12 \mathrm{pm}$.

Several programs have also focused on encouraging women to create small-scale business including crafting crafts, jute bags, and helped them become entrepreneurs. For this show, experts from the particular field are invited and by telephonic interviews listeners are allowed to interact with them.

There are other shows for women during afternoon, where doctors from all fields are invited to share information and spread awareness for health related issues. This show also helps listeners to clarify their doubts by discussing with experts by phone calls.

Shows focusing on the achievements of women from various fields, such as IAS, IPS, doctors, advocates, police officers, human rights and sports persons, are also produced to generate positive impacts and motivate women towards their own development.

Women related programs have also been produced by the youth section for the past four months at a minimal level on themes such as women's safety, women-based laws, and more.

\section{Role of radio in women's development.}

- For women's development, every woman should an active participant in order to create change. In India there is only $50 \%$ development, and still awareness and information needs to be widespread.

- In achieving this goal, radio plays a vital role in carrying information to every woman. Also there is no use in providing information to the already empowered people.

- The reach of AIR in India is very vast and radio can be heard in remote villages, coastal, agricultural and forest areas. In fact, radio is observed to overcome television medium especially during natural disasters.

- The role of radio in women's development is more effective when they broadcast development programs, therein creating a positive impact among the listeners. Generally the role of radio in women's development is very remarkable, as true situations need to be analysed and genuine information must be provided.

- Women, particularly those who are engaged in handwork like weaving, tobacco leaf rolling and working in the brick chambers, listen to the radio in their working place.

- After the introduction of private TV channels, they watched megaserials and listening to radio became a rare activity. College girls prefer to listen to FM radio during their traveling time. 
- AIR is the only Radio channel mounting programmes especially for women's development and listening to such special audience programmes were reduced due to the influence of TV mega serials.

- AIR is giving equal importance in all aspects for women's development. Through its programs and in the selection of RJs and focusing on day to day problems faced by women community in the modern society.

Table 5 discusses the relative levels of importance that Radio Jockeys give to women oriented radio programs.

Table 5. Importance Given to Women Focused Programs by RJs in FM Rainbow

\begin{tabular}{|c|c|c|c|}
\hline \multirow{2}{*}{$\begin{array}{l}\text { No of Radio } \\
\text { Jockeys (RJ) }\end{array}$} & \multicolumn{2}{|r|}{ Type of Programs } & \multirow{2}{*}{$\begin{array}{l}\text { Objectives fulfilled } \\
\text { not fulfilled }\end{array}$} \\
\hline & General (\%) & Women related programs $(\%)$ & \\
\hline RJ 1 & 20 & 80 & Fulfilled \\
\hline RJ 2 & 80 & 20 & Not fulfilled \\
\hline RJ 3 & 60 & 40 & Not fulfilled \\
\hline RJ 4 & 30 & 70 & Fulfilled \\
\hline RJ 5 & 40 & 60 & Fulfilled \\
\hline
\end{tabular}

\section{In-depth Interview - Private Radio Sector}

Here the views shared by people working in private radio stations, such as Radio City, Hello FM, Suryan FM and Big FM, regarding women's development, women related programs and the role of radio in women's development are given.

Women's development in India. Relieving Indian women from the existing social and cultural restrictions fosters the developmental process to grow with ease and at a rapid speed. It is evident that development of women in India is gradually increasing in several domains, the achievements of Indian women in the 2016 Olympics is one such example.

Emotional attachment and dependence are identified as the major factors hindering the process of women's development in India. Also it is vital to note that women in rural areas, especially in the northern part of the country, are deprived of all developmental initiatives. Support from family members and work environment tend to play crucial roles in the development process.

Indian women are able to easily adapt and develop themselves in this modern era. The crux of women's development lies in accepting the fact that men and women are equal. The radio industry is one of the many fields that promotes and supports women's developmental opportunities and activities.

Education and independence are the two core elements of women's empowerment. Hence enhancing self-employment opportunities and providing basic education are the primary requirements for a developing country like India. The lack of safety and the prevalence of insecure feelings among Indian women are noted to be crucial entities hindering the process of development.

In India, more opportunities are required in fields like politics, research, science, and sports to nurture women's development. Many women are talented and eager to showcase their talents, but there is a lack of opportunities and 
platforms in the nation. For instance, even homemakers are trying to showcase their work by running small businesses and freelance works.

In comparison to former eras, currently a lot of importance is given to developmental initiatives by providing multiple platforms for women to voice their opinions and exercise their rights. Similarly, women in the media industry strive to shine, despite the challenges faced in a male-dominated industry. In addition to the media industry, software, transport, management, marketing and airways are also witnessing a similar trend.

Women related programs. Women centric programs in private radio stations primarily focus on themes such as the promotion of women's health, selfdefence and post marriage problems to name a few. Occasionally, these stations organize awareness programs like marathons ("pinkathon-marathon") in relation to women's health. Also, interviews from doctors, yoga experts, psychiatrists, young entrepreneurs, police and women achievers are included in women-centric programs. These programs in general tend to yield positive responses (receiving feedbacks, sharing experiences and participation) from the target audience women listeners (home makers, working women and college students) - regularly. Interviews of women achievers in sports are also given importance in these women centric programs.

Recently, a private FM ran a show interviewing India's first woman grand master in chess. Other women achievers such as social activists, small-scale business women, auto drivers, bus conductors etc. are also interviewed in order to motivate women listeners.

Government job opportunities available for sport athletes are also highlighted in these programs encouraging and motivating the listeners to pursue the field. Female entrepreneurs are also given importance in several women centric programs. Other than promoting gender specific programs, radio jockeys perceive that it is crucial to raise questions relating to women's issues in all radio programs that might enable the listeners to call and discuss their experiences and problems irrespective of gender specific programs.

In private FM stations, male radio jockeys are also handling women centric programs. Listeners tend to pay special attention to these programs because of an opposite gender radio jockey. Apart from cooking programs, these programs also include outdoor broadcasting for disseminating information on diverse topics, such as medicinal values of food products, adulterated products in markets and beauty tips from dermatologists. Owing to legal restrictions, private FM stations in India are not permitted to air news. Thus instead of airing news directly, FM stations air programs dealing with important societal issues and initiate discussions among the listeners.

In addition to these shows, programs providing opportunities for women to showcase their talent are also aired on FM channels. A private FM station in Chennai conducted a fitness event ("Radio City Super Women") aiming to foster women's health and safety by teaching women self-defence techniques and a fitness regime. The event was a grand success, receiving much positive feedback from the listeners through Facebook and phone-in programs. Outdoor events such 
as radio jockey's road trips with a large group of female listeners are also conducted by these FM stations for boosting confidence of women.

Gender specific career guidance is another type of program that is usually given more importance in private radio stations. These programs tend to provide detailed information through interviews conducted with women experts present in a specific field, such as Vfx, Software or Theatre. Another important initiative done by private FM stations includes training programs and workshop conducted for women's empowerment. Workshops regarding small-scale business, such as tailoring, handicrafts, and the process of business loan applications are generally conducted periodically.

Online media plays a major role in the radio industry in terms of posting updates regarding shows, conducting online discussions and receiving feedback from listeners. Also, online web radio that can be launched using advanced digital technology aids in expanding the stations' listenership worldwide, while social media platforms such as Facebook are used as stabilizing tools between traditional and online radio broadcasting. For instance, prior to airing radio programs, the private radio stations update the theme and topics of their programs in social media outlets, thereby updating and motivating the listeners to tune in to their channel for the program and share their views/opinions. Facebook videos are also popularly used by FM channels primarily for providing a recap of the radio programs for listeners who did not listen during the scheduled time.

Role of radio in women's development. According to the programming heads and radio jockeys of private FM stations in Chennai, radio plays a crucial role in creating awareness and broadcasting information regarding gender specific issues. Women radio jockeys in private FM stations are keen towards broadcasting special programs relating to women's education and independent lifestyle instead of focusing on cliché topics such as cooking and beauty tips. They perceive radio as an information transmitting medium to deliver content that aids in increasing the knowledge level of women listeners, especially homemakers, on education, financial independence and other women specific opportunities available.

Private FM stations also tend to host discussions on key gender issues, thereby providing a medium for the audience to voice their opinions and initiate positive change in societal ideologies. In comparison to any other media outlets, radio can be observed to broadcast women focused programs at a high level giving more importance to women centric issues. Being a user friendly medium, radio is perceived to motivate talents, build confidence and improve the livelihood of women listeners.

\section{Findings and Conclusion}

In India, irrespective of the measures taken for women's development, the actual impact is still at a minimal level (Agarwal, 2008). AIR was identified as a powerful medium to grab the attention of the women listeners through various 
program genres and radio content. Women focused programs are aired in AIR for focusing on harassment and violence aiming to give solutions to overcome such situations. In addition, AIR also concentrates on projecting positive images of women in their programs (Rathod, 2009). The development programs for women in radio motivated them and created a positive influence. Radio plays a vital role in the development of women by analysing the actual scenario and providing genuine information. Radio programs act as tools for sharing knowledge and information intended for women's development for achieving gender equality (Baruah, 2017). AIR encourages women to work in all sectors without any hesitation by giving valuable programs according to the listener's choice, and it is giving equal importance in all the aspects for women's development. Through their large geographical reach, AIR provides a lot of awareness and motivation among women in both urban and rural areas. Also, in the current technological era, AIR attains its peak by providing programs supported by all existing technological platforms.

Private FM stations mostly use social media as a tool to popularise their programs and events conducted for women's development. Social media changes the dimension of radio from invisible to visible medium by uploading pictures, videos and graphics of programs in social networking sites like Facebook (Bosch, 2013). Private FM stations in Chennai also indulge in outdoor activities for training women in self-defence, health and fitness other than just airing women-focused programs. The RJs are doing Outdoor Broadcasting about the new products in the market and medicinal values in food products. Workshops conducted by private radio stations for household women aim to improve their economic status and help them lead their life independently. In comparison to other programs, women oriented programs receive positive feedback and entertain the listeners by giving them useful information. The interviews of female experts and achievers are intended to motivate listeners in their respective fields. Private FM stations majorly broadcast discussion-based programs examining the key gender issues, thereby helping the women to express their views and opinions. Both public and private radio stations provide many women related programs in different genres for the benefit and uplift of women's lives. In addition, the public service radio broadcaster (AIR) and the private radio stations conduct events to encourage the listeners to showcase their talents and enrich their entrepreneurial journey.

Rogers (2003) formulated the diffusion of innovation theory that outlines the four major factors - invention, diffusion or communication through the social system, time and consequences - that influence the society to accept and utilize a particular innovation. Any new innovation in general is observed to travel through five different types of adopters, namely innovators, early adopters, early majority, late majority and laggards, under the influence of mediators such as gatekeepers, opinion leaders and intermediaries. As per the theory, innovation takes a few stages and steps to reach the target audience. The present study is in agreement to the theory. The programs analysed and the interviews conducted indicate that the radio has the potential to reach women 
of all classes, and it possesses the power to motivate and guide them in all spheres of life.

\section{Bibliography}

Agarwal, B. (2008). Rural Women in Indian Economy. Jaipur: ABD Publishers.

Amoedo, A. (2010). Redefining Regional Public Radio in Spain: Challenges of the Public Radio of the Autonomous Regions (1982-2007). Comunicación y Sociedad, 23(1), 105-120.

Baruah. U. L. (2017). This is All India Radio. New Delhi: Ministry of Information and Broadcasting.

Bhatnagar, R. (2001). India's Media and Modern Journalism. New Delhi: Indian Publishers and Distributers.

Bell, E. (2008). "No one wants to be lectured at by a woman": Women and history on TV. Women's History Magazine, 59, 4-11.

Bora, A. (2011). Public Service Broadcasting by Radio: Challenges Ahead. New Media and Mass Communication, 6, 3-5.

Bosch, T. (2013). Women as radio audiences in Africa. In Carter, C., Steiner, L., \& McLaughlin, L. (Eds.). The Routledge Companion to Media \& Gender, 514-522. London: Routledge.

Chatterji, Z. (2008). Radio broadcasting in India. In Krishnamurthy. H., Phatak. B. D., Kochhar. S, \& Dhanjal. G. (Eds.), Infrastructure and Governance, 95-100. India: Academic Foundation.

Kumar, R., \& Singh, A. K. (2008). Women Empowerment and Development Discourse in India. In Soni. J. K. (Eds.), Women Empowerment The Substatantial Challenges, 23-44. New Delhi: Authorspress.

Kumar, R. (2013). Public Service Broadcasting System in India: Diversity and Pluralism in Media. Pragyaan: Journal of Mass Communication, 11(2), 13-20.

Lai, C. N. (2014). Public broadcast of health communication: Extending public relations through social capital in Taiwan. Public Relations Review, 40(3), 506-508.

Lacey, K. (2006). Continuities and Change in Women's Radio. In A. Crisell (Eds.), More Than a Music Box: Radio Cultures and Communities in a Multi-Media World, 145-164. New York: Berghahn Books.

Mitchell, C. (2008). "Dangerously Feminine?" Theory and Praxis of Women's Alternative Radio. In Ross, K., \& Byerly, C. M. (Eds.), Women and media: international perspectives, 157-182. London: John Wiley \& Sons.

Odunola, A. H., Babafemi, A. J., Lois, A. J. (2015). The Role of Radio in the Mobilization of Women towards Political Participation: A Study of Ogun State Nigeria. Research on Humanities and Social Sciences, 5(24), 11-18.

Ranganathan, M. (2010). Commercial FM radio takes over Indian Cities. In Ranganathan. M., \& Rodrigues. U. M. (Eds.), Indian Media in a Globalised World, 69-83. India: Sage Publications.

Rathod, P. B. (2009). Women and Development. Jaipur: ABD Publishers.

Rogers, E. M. (2003). Diffusion of Innovations. New York: Free Press.

Sharma, A. (2015). Community Radio for Women Empowerment, 25-30. India: Biotech Books. 
Vol. 4, No. 2 Rasheed et al.: A Study on the Role of Public and Private Sector Radio...

Skoog, K. (2009). "Focus on the Housewife": the BBC and the Post-war Woman, 1945-1955. Networking Knowledge: Journal of the MeCCSA Postgraduate Network, 2(1). Retrieved from goo.gl/e6TvVV.

Somolu, O. (2013). Radio for Women's Development - Examining the Relationship between Access and Impact. Nokoko, Institute of African Studies, Carleton University (Ottawa, Canada) 3. Retrieved from goo.gl/EK9f4e.

Thomas, P. N. (2013). Redeeming All India Radio: Public (Service) Broadcasting and Communication Rights. Economic and Political Weekly, 48(31), 34-39.

Thussu, D. K. (1999). Privatizing the airwaves: The impact of globalization on broadcasting in India. Media, Culture \& Society, 21(1), 125-131.

Vickery, A. (2016) Woman's Hour was launched 70 years ago - but the BBC almost got it totally wrong. Retrieved from goo.gl/sAVSq4. 